\title{
Combined effect of noise and vibration produced by high-speed trains on annoyance in buildings
}

\author{
Pyoung Jik Lee ${ }^{a)}$ and Michael J. Griffin \\ Human Factors Research Unit, Institute of Sound and Vibration Research, University of Southampton, \\ Highfield, Southampton, SO17 1BJ, United Kingdom
}

(Received 30 July 2012; revised 4 February 2013; accepted 7 February 2013)

\begin{abstract}
The effects of noise and vibration on annoyance in buildings during the passage of a nearby high-speed train have been investigated in a laboratory experiment with recorded train noise and $20 \mathrm{~Hz}$ vibration. The noises included the effects of two types of façade: windows-open and windows-closed. Subjects were exposed to six levels of noise and six magnitudes of vibration, and asked to rate annoyance using an 11-point numerical scale. The experiment consisted of four sessions: (1) evaluation of noise annoyance in the absence of vibration, (2) evaluation of total annoyance from simultaneous noise and vibration, (3) evaluation of noise annoyance in the presence of vibration, and (4) evaluation of vibration annoyance in the absence of noise. The results show that vibration did not influence ratings of noise annoyance, but that total annoyance caused by combined noise and vibration was considerably greater than the annoyance caused by noise alone. The noise annoyance and the total annoyance caused by combined noise and vibration were associated with subject self-ratings of noise sensitivity. Two classical models of total annoyance due to combined noise sources (maximum of the single source annoyance or the integration of individual annoyance ratings) provided useful predictions of the total annoyance caused by simultaneous noise and vibration.
\end{abstract}

C 2013 Acoustical Society of America. [http://dx.doi.org/10.1121/1.4793271]

PACS number(s): 43.50.Qp, 43.40.Ng, 43.66.Wv [NX]

Pages: 2126-2135

\section{INTRODUCTION}

Train-induced noise and vibration in buildings can cause adverse physical, physiological, and psychological effects on humans in dense urban environments. Studies have shown that exposure to train noise and vibration causes annoyance to residents of nearby buildings (e.g., Fields and Walker, 1982; Fields, 1979). Since the 1960s, the introduction of the high-speed train has produced additional environmental concerns because they produce different characteristic noise and vibration from conventional trains due to their high speeds.

Noise problems caused by conventional trains have been investigated mainly through the use of social surveys in terms of dose-response curves (Fields, 1979; Moehler, 1988; Miedema and Vos, 1998; Öhrström et al., 2010) and railway noise was found to be less annoying than road traffic noise with the same sound pressure level. Therefore, lower limit values for railway traffic than for road traffic noise were applied in noise regulations (known as the "railway bonus"). Furthermore, a community tolerance level has been newly proposed to predict the prevalence of annoyance caused by transportation noise based on social surveys of road and rail noise (Schomer et al., 2012). Similarly, several studies (Lambert et al., 1996; Chen et al., 2007) examined the difference in annoyance between conventional and high-speed trains and magnetic levitation (maglev) also using social surveys. Laboratory experiments were also conducted to determine the effects of noise level and source type on

\footnotetext{
${ }^{\text {a) }}$ Author to whom correspondence should be addressed. Also at: EMPA, Swiss Federal Laboratories for Materials Science and Technology, 8600, Dübendorf, Switzerland. Electronic mail: pyoungjik@daum.net
}

annoyance induced by both conventional and high-speed trains in simulated environments (Kurra et al., 1999, Vos 2004; De Coensel et al., 2007; Yoo et al., 2010). It was observed that noise annoyance caused by conventional trains was not significantly lower than annoyance caused by highspeed trains (De Coensel et al., 2007) but high-speed train noise was less annoying than maglev noise (Vos, 2004).

Noise is not the only variable causing annoyance, and a number of studies have dealt with railway noise associated with railway-induced vibration because trains often produce significant vibrations that are transmitted to buildings in the vicinity. The effects of conventional train induced noise and vibration on the community have been reported in terms of annoyance and interference with activity through surveys (Fields, 1979; Woodroof and Griffin, 1986; Zapfe et al., 2009; Klæboe et al., 2003; Peris et al., 2012). Community responses to noise and vibration caused by high-speed trains have also been investigated using social surveys, with studies carried out mainly in Japan (Yano et al., 2005; Yokoshima and Tamura, 2005; Yokoshima et al., 2011). The results showed that high-speed train noise was more annoying than conventional train noise (Yano et al., 2005) and vibration led to greater noise annoyance (Yokoshima and Tamura, 2005; Yokoshima et al., 2011). However, the vibrations were only measured in the ground and the contribution of vibration to noise annoyance was not clarified.

A series of laboratory experiments dealt with combined noise and vibration from railways using vertical ( $z$-axis) vibrations measured in buildings. The relative importance of noise and vibration was investigated and a subjective equivalence contour was derived (Howarth and Griffin, 1990a). Subjective responses to combinations of six levels of noise and six 
magnitudes of vibration were examined and the summation and interaction effects of the two stimuli were then determined (Howarth and Griffin, 1990b). In a third experiment, the total annoyance caused by combined noise and vibration was investigated and it was found that total annoyance could be predicted by combining the individual effects of the two stimuli (Howarth and Griffin, 1991). Furthermore, the combined effects of noise and vibration on rated intensity and annoyance have been explored using tram-induced noise and vibration (Paulsen and Kastka, 1995). These studies, however, were focused on noise and vibration from conventional trains and trams, and the variable attenuation of building façades that can change the sound pressure levels of noise was not considered.

The present study was designed to investigate the effect of vibration on noise annoyance and to examine the total annoyance caused by noise and vibration in the vicinity of high-speed trains. Levels of noise and magnitudes of vibration in buildings vary according to distance from a railway track, so two façade attenuations were applied to sound stimuli on the assumption that the attenuation of the façade structure affects the annoyance inside a building. During the laboratory experiments, subjects were exposed to noise and vibration from high-speed trains and rated their annoyance level using an 11-point numerical scale.

\section{METHODS}

\section{A. Stimuli}

Sound stimuli were recordings of sound during the passage of a high-speed train traveling at $250 \mathrm{~km} / \mathrm{h}$. The noise was recorded in Korea using a dummy head (Type 4100, $\mathrm{B} \& \mathrm{~K})$ at a distance of $25 \mathrm{~m}$ from the railway line. Dichotic stimuli were prepared using only the left channel signals of the binaural recordings to exclude the spatial aspects of the recording. A 45-second period containing a single train passage was extracted from the recording. The passage of the high-speed train lasted about $8 \mathrm{~s}$ with silent periods of about $18 \mathrm{~s}$ before and after the train passage. The equivalent continuous level $\left(L_{\mathrm{Aeq}, 45 \mathrm{~s}}\right)$ of the selected noise was found to be around $96.0 \mathrm{~dB}$. For the preparation of stimuli with levels lower than the originally recorded noise, the spectral content was adjusted taking into account source-to-receiver distance $(35,50,75,100$, and $150 \mathrm{~m})$ and air absorption (ISO 9613-1, 1993). The calculations were performed for meteorological conditions with a temperature of $20{ }^{\circ} \mathrm{C}$ and a relative humidity of $55 \%$. Outdoor A-weighted sound exposure levels $\left(L_{\mathrm{AE}}\right)$ for sound stimuli corresponding to source-to-receiver distances of $35,50,75,100$, and $150 \mathrm{~m}$ were 96.0, 93.1, $90.3,86.5,84.0$, and $80.5 \mathrm{~dB}$, respectively.

For the façades, spectral filtering was applied to simulate the various frequency-dependent outdoor-to-indoor noise attenuations. Among various types of façade attenuations (Vos, 2003; Lee et al., 2010), the closed window with a median degree of isolation and wide-open window were adopted and sound reductions are plotted in Fig. 1. For the wide-open window, an attenuation of $5 \mathrm{~dB}$ was applied in the frequency range $12.5-1000 \mathrm{~Hz}$ and the attenuation increased to $8 \mathrm{~dB}$ at higher frequencies. The façade

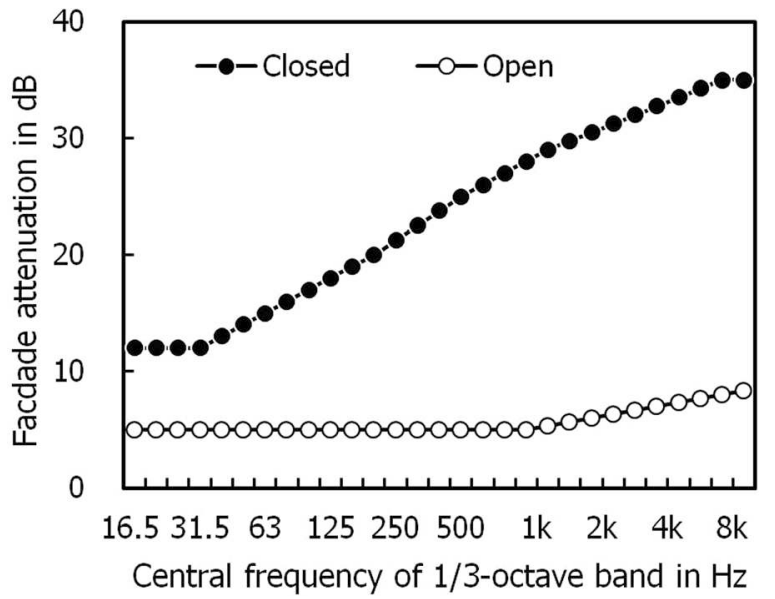

FIG. 1. Façade attenuations for windows-open and windows-closed conditions.

attenuation increased from $12 \mathrm{~dB}$ at 16 and $31.5 \mathrm{~Hz}$, up to $35 \mathrm{~dB}$ at $8 \mathrm{kHz}$ for the closed window with a median degree of isolation. The frequency characteristics of the sound stimuli after spectral filtering are shown in Fig. 2. The spectral characteristics of the sound stimuli for the windows-open condition were dominated by high-frequency and lowfrequency components, but the energy at high frequency was significantly decreased for the stimuli in the windows-closed condition. The background noise used in the experiment was road traffic noise at $35 \mathrm{~dB}$ in terms of A-weighted sound
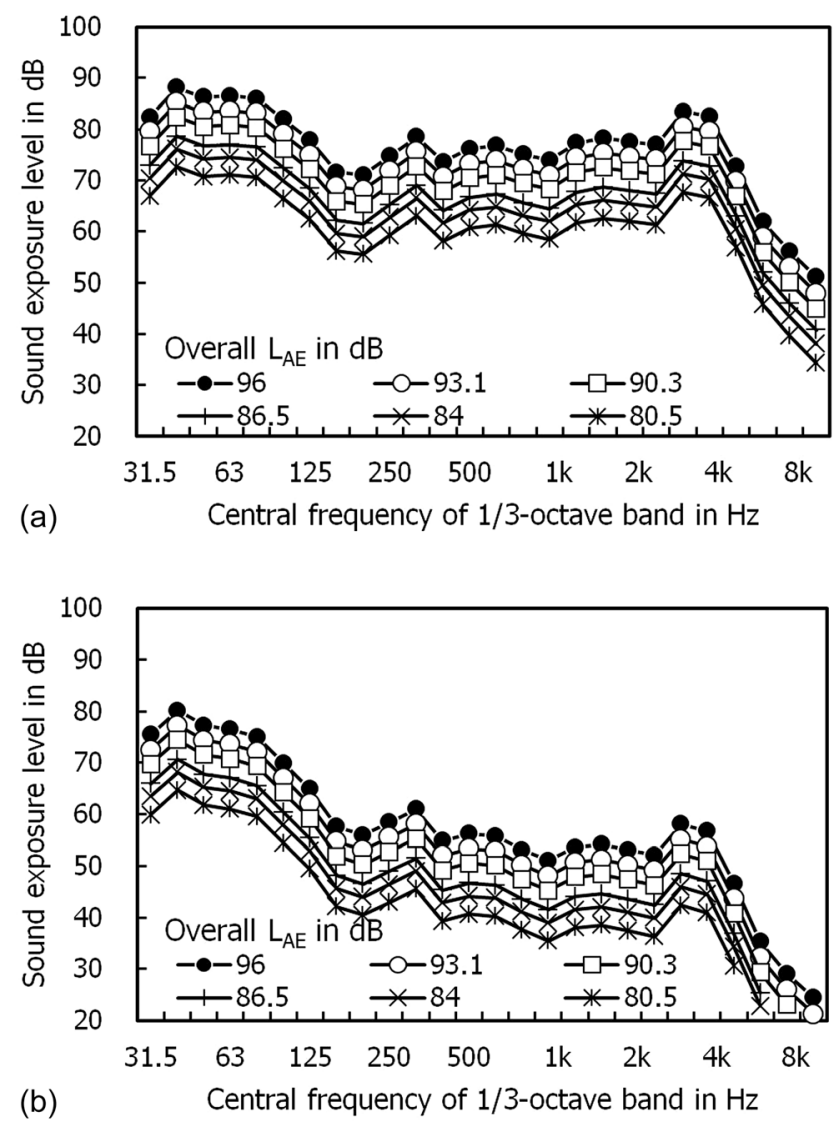

FIG. 2. Frequency characteristics of sound stimuli for windows-open condition (left) and windows-closed condition (right). 
pressure level. The spectral characteristics of the background noise are presented in Fig. 3.

Instead of using outdoor recordings, vibration stimuli were generated in the laboratory using the HVLAB data acquisition and analysis system. The fundamental resonances for typical wood-frame residential structures and reinforced-concrete slab floors are in the $15-20$ and $20-30 \mathrm{~Hz}$ ranges, respectively (Jones, 1994). Ju (2007) reported that $20 \mathrm{~Hz}$ is a dominant frequency of building vibration induced by high-speed trains. Therefore, sinusoidal signals of $20 \mathrm{~Hz}$ were selected as vibration stimuli in the present study. The amplitude of the vibration stimuli increased and decreased over a duration of $8 \mathrm{~s}$, with two peaks in a similar manner to the simultaneous noise stimuli. As shown in Fig. 4(b), the amplitude was increased from zero to a first peak at $2 \mathrm{~s}$, then decreased by $30 \%$ to a trough at $3.5 \mathrm{~s}$, followed by an increase to the same magnitude as the first peak at $5 \mathrm{~s}$, followed by a decrease to zero at $8 \mathrm{~s}$. All changes in vibration amplitude followed a cosine taper, with the maximum rate of change of amplitude midway through the change. The magnitudes of vibration stimuli were predicted according to a simple prediction model suggested by DOT-293630-1 (Hanson et al., 2005). First, the ground vibration levels were estimated taking into account factors affecting the vibration source, such as train speed $(250 \mathrm{~km} / \mathrm{h})$ and wheels. Factors affecting the vibration path and receivers were then used in estimating building vibration levels. For this experiment, it was assumed that the buildings were woodframe structures and the listener was located on the second floor. Levels for vibration stimuli are listed in Table I in terms of unweighted root-mean-square (rms) acceleration in $\mathrm{ms}^{-2}$ and unweighted vibration dose value (VDV) in unit of $\mathrm{ms}^{-1.75}$ (ISO 2631-1, 1997).

\section{B. Apparatus}

Vertical (z-axis) whole-body vibration was generated by an electrodynamic vibrator (Derritron VP85) and subjects sat on a rigid wooden seat $(250 \mathrm{~mm} \times 180 \mathrm{~mm})$ with a contoured surface in order to provide contact with the ischial tuberosities. The subjects were asked to maintain their upper body in a roughly vertical posture with their hands on their knees and their feet on stationary footrests. There was no

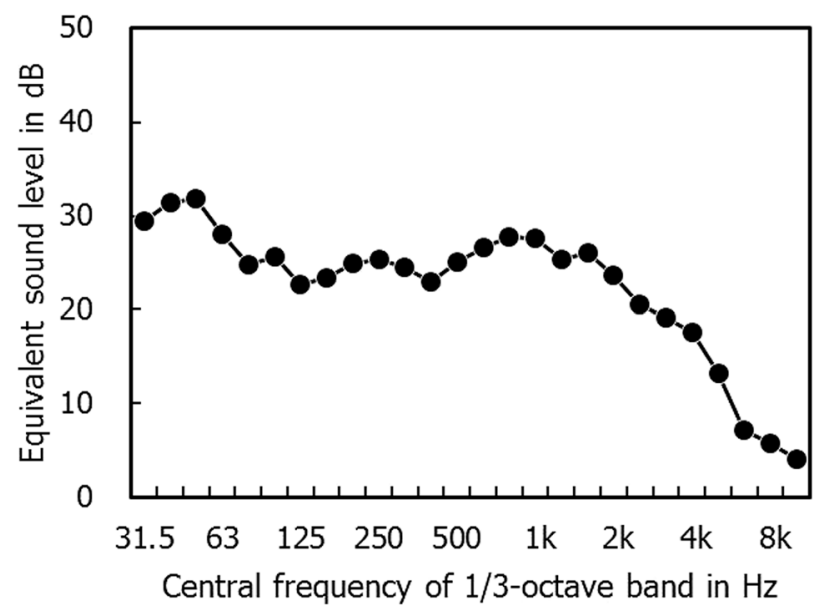

FIG. 3. Frequency characteristics of background noise.
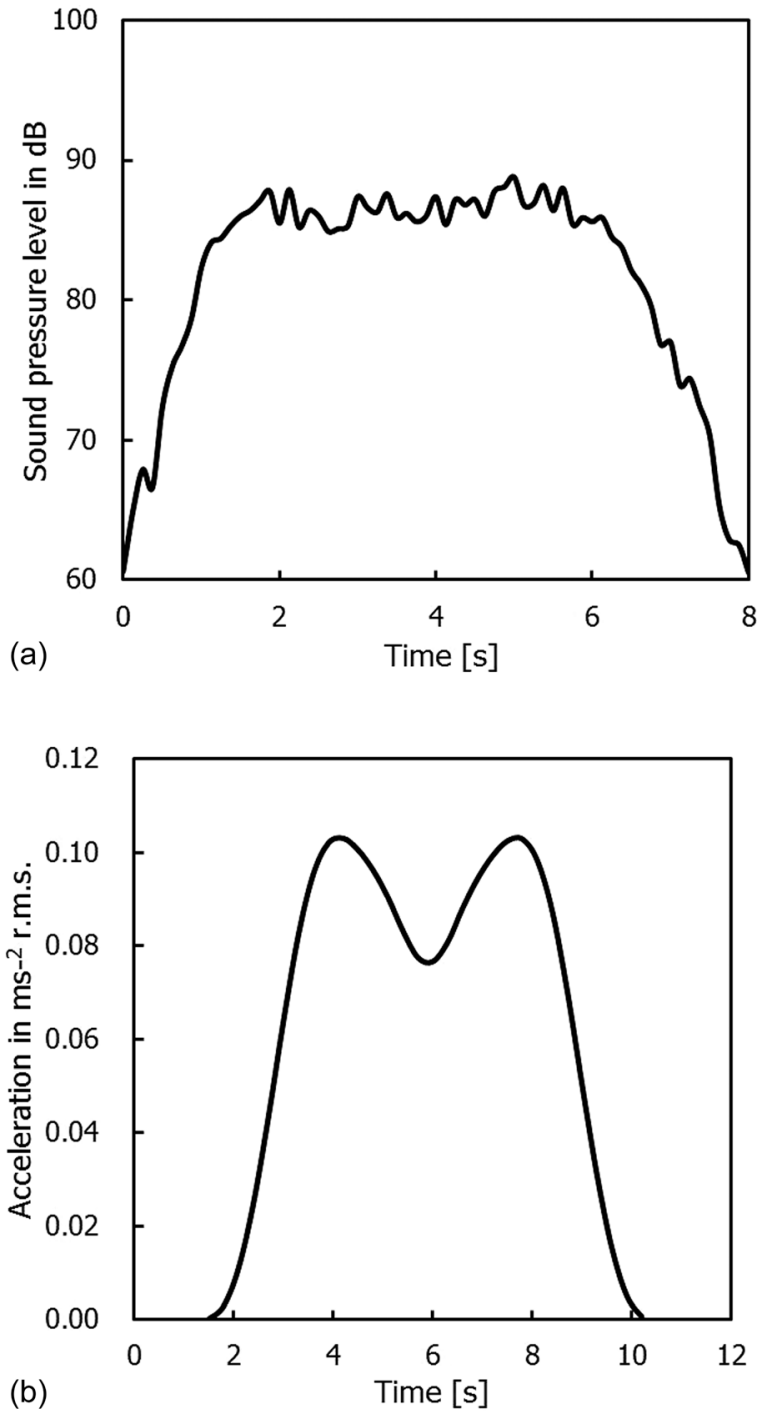

FIG. 4. Time histories of the typical noise and vibration stimulus: (a) noise stimulus and (b) vibration stimulus.

backrest and no significant vibration was transmitted to other parts of the subjects' bodies.

Sound stimuli were presented through headphones. The headphones used in this study had a frequency response of $32-4000 \mathrm{~Hz} \pm 2 \mathrm{~dB}$. The sound preproduction system was calibrated using a pink noise signal, which was measured at the location of the subject's ear. The sound stimuli were played directly from a PC via a digital-to-analog converter to headphones, and recorded using a KEMAR head with two artificial ears.

TABLE I. Levels of noise and vibration stimuli according to source-toreceiver distance.

\begin{tabular}{lcccccc}
\hline \hline & \multicolumn{5}{c}{ Source-to-receiver distance [m] } \\
\cline { 2 - 7 } & 25 & 35 & 50 & 75 & 100 & 150 \\
\hline Outdoor $L_{\mathrm{AE}}[\mathrm{dB}]$ & 96.0 & 93.1 & 90.3 & 86.5 & 84.0 & 80.5 \\
Unweighted rms & 0.079 & 0.053 & 0.036 & 0.020 & 0.014 & 0.008 \\
Acceleration level $\left[\mathrm{m} / \mathrm{s}^{2}\right]$ & & & & & & \\
Unweighted VDV $\left[\mathrm{ms}^{-1.75}\right]$ & 0.160 & 0.113 & 0.072 & 0.042 & 0.029 & 0.016 \\
\hline \hline
\end{tabular}




\section{Subjects}

A total of 20 subjects (10 males and 10 females) participated in the experiment. Subjects with different nationalities (10 Korean and 10 British) were selected because there was an expectation that Korean subjects would be more familiar with high-speed trains than British subjects. The subjects' ages ranged from 20 to 35 years (mean: 26.2, standard deviation: 5.9 for Korean and mean: 24.1, standard deviation: 3.7 for British). Before the experiment, brief interviews were conducted to collect data on experience of traveling by highspeed train and sensitivities to noise and vibration. The selfratings of noise sensitivity were requested on an 11-point numerical scale using the following single-item question (Zimmer and Ellermeier, 1999; Ryu and Jeon, 2011): "How would you describe your sensitivity to noise?" Vibration sensitivity was determined using a similar question. Subjects gave informed consent to participate in the experiment that was approved by the Ethics Committee of the Faculty of Engineering and the Environment at the University of Southampton.

\section{Procedure}

The laboratory experiment was performed to investigate the combined effect of noise and vibration on annoyance. Similar to studies of audio-visual interactions, which have compared sound perceptions in conditions with and without visual appearances (Viollon et al., 2002; Jeon et al., 2012), this experiment was designed to include sessions with and without the presence of vibration so as to assess the effect of the presence of vibration on noise annoyance. As listed in Table II, the experiment consisted of four sessions: (1) evaluation of noise annoyance without the presence of vibration, (2) evaluation of total annoyance of noise and vibration, (3) evaluation of noise annoyance with the presence of vibration, and (4) evaluation of vibration annoyance. Each subject

TABLE II. Evaluation required and stimuli for the four sessions of the laboratory experiment.

\begin{tabular}{|c|c|c|}
\hline Sessions & Evaluation & Noise and vibration stimuli \\
\hline Session 1 & Noise annoyance & $\begin{array}{l}\text { Six levels of noise } \\
\text { (windows-open) } \\
\text { Six levels of noise } \\
\text { (windows-closed) }\end{array}$ \\
\hline Session 2 & Total annoyance & $\begin{array}{c}\text { Six levels of noise } \\
\text { (windows-open) } \\
\text { with six levels of vibration } \\
\text { Six levels of noise } \\
\text { (windows-closed) } \\
\text { with six levels of } \\
\text { vibration }\end{array}$ \\
\hline Session 3 & Noise annoyance & $\begin{array}{c}\text { Six levels of noise } \\
\text { (windows-open) } \\
\text { with six levels of vibration } \\
\text { Six levels of noise } \\
\text { (windows-closed) } \\
\text { with six levels } \\
\text { of vibration }\end{array}$ \\
\hline Session 4 & Vibration annoyance & Six levels of vibration \\
\hline
\end{tabular}

J. Acoust. Soc. Am., Vol. 133, No. 4, April 2013 attended the four sessions on two separate days: sessions 1 and 2 on the first day of the experiment and sessions 3 and 4 during the second day. Each subject was exposed to a total of 42 stimuli, with 12 noise stimuli (session 1), 24 combinations of simultaneous noise and vibration stimuli (sessions 2 and 3), and six vibration stimuli (session 4). Stimuli were randomly presented to subjects to balance order effects, and the subjects participated in each test session twice in order to enhance the reliability.

During the experiment, subjects were asked to rate their annoyance using an 11-point numerical scale (with 0 as "not at all" and 10 as "extremely") as in previous studies (Jeon et al., 2010; Jeon et al., 2011) according to the following instruction: "Please rate each stimulus on an 11-point scale according to your annoyance assuming that you are exposed to it at home." They were instructed to consider everything that they heard and felt for the $45 \mathrm{~s}$ period, and asked to imagine that there was around twenty train pass-bys per hour during the day time. A task was not given to the subjects in this experiment and subjects were asked to relax as much as possible during the experiment. Prior to beginning the experiment, two movie clips of passing trains accompanying the recorded sounds were presented to the subjects, and each subject attended an orientation session to familiarize themselves with the stimuli and evaluation using the 11-point numerical scale.

\section{E. Statistical analysis}

All statistical analyses were carried out using sPss for Windows, version 20.0 (SPSS, Inc., Chicago, IL). An analysis of variance model was adopted to examine (1) whether the replications had an influence on annoyance ratings, (2) whether the presentation of vibration affected noise annoyance, and (3) any significant differences between noise annoyance and total annoyance. Independent samples $t$-tests were also used to investigate any effects of subject ethnicity (Korean and British) and sensitivity to noise (low and high). Linear regression analysis was performed to derive regression models for predicting total annoyance caused by noise and vibration stimuli.

\section{RESULTS}

Analysis of variance was used to estimate the significances of differences in in annoyance ratings across replications (first and second responses) and levels of noise. Comparisons of the first and second ratings indicated that mean annoyance scores obtained in the first responses were not significantly different from those obtained from the second responses ( $p>0.10$ for all sessions), and there were no significant first order or second order interaction effects between replication and noise levels ( $p>0.10$ for all sessions). Mean correlation coefficients between the first and second ratings for each subject ranged from 0.81 to 0.87 for noise and vibration annoyance. Subjective responses were averaged across subjects and across replications in the detailed analysis.

\section{A. Effect of façade insulation on noise annoyance}

Figure 5 indicates the noise annoyance ratings for tests without the presence of vibration as a function of outdoor 


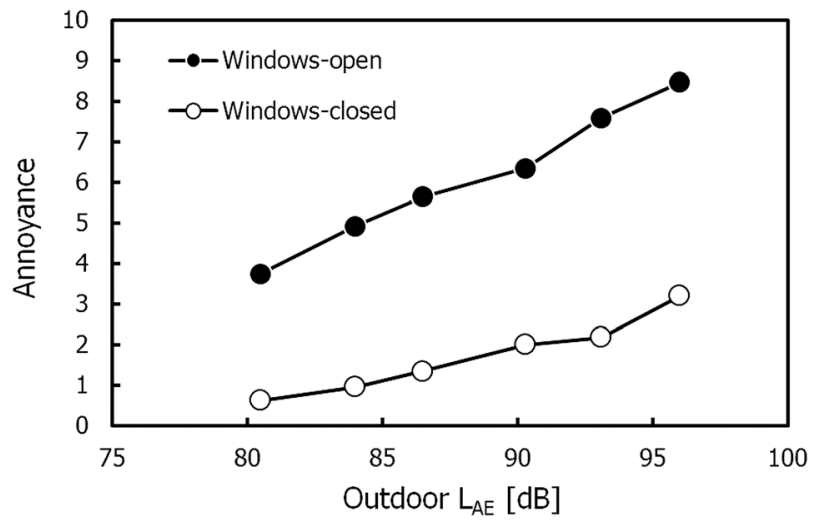

FIG. 5. Mean noise annoyance ratings for tests without the presence of vibration as a function of outdoor $L_{\mathrm{AEs}}$.

$L_{\mathrm{AE}}$. The mean annoyance scores and the standard errors are listed in Table III. It was found that noise annoyance ratings increased as sound pressure level increased, and ratings for the windows-open conditions were significantly greater than those for the windows-closed condition $(p<0.01)$. The difference between the annoyance ratings for façade insulations slightly increased with increasing sound pressure level. Correlation coefficients between noise annoyance ratings and outdoor $L_{\mathrm{AEs}}$ for the windows-open and windows-closed conditions were 0.98 and $0.96(p<0.01$ for all), respectively.

\section{B. Effect of presence of vibration on noise annoyance}

In order to investigate the effect of vibration on noise annoyance, noise annoyance ratings obtained from sessions 1 and 3 were compared. As shown in Figs. 6(a) and 6(b), noise annoyance ratings for noise-only sessions were similar to the ratings for the sessions with vibration in both windows-open and windows-closed conditions. Results of an analysis of variance $[2$ sessions $\times 6$ sound pressure levels] confirms that the effect of the presence of vibration on
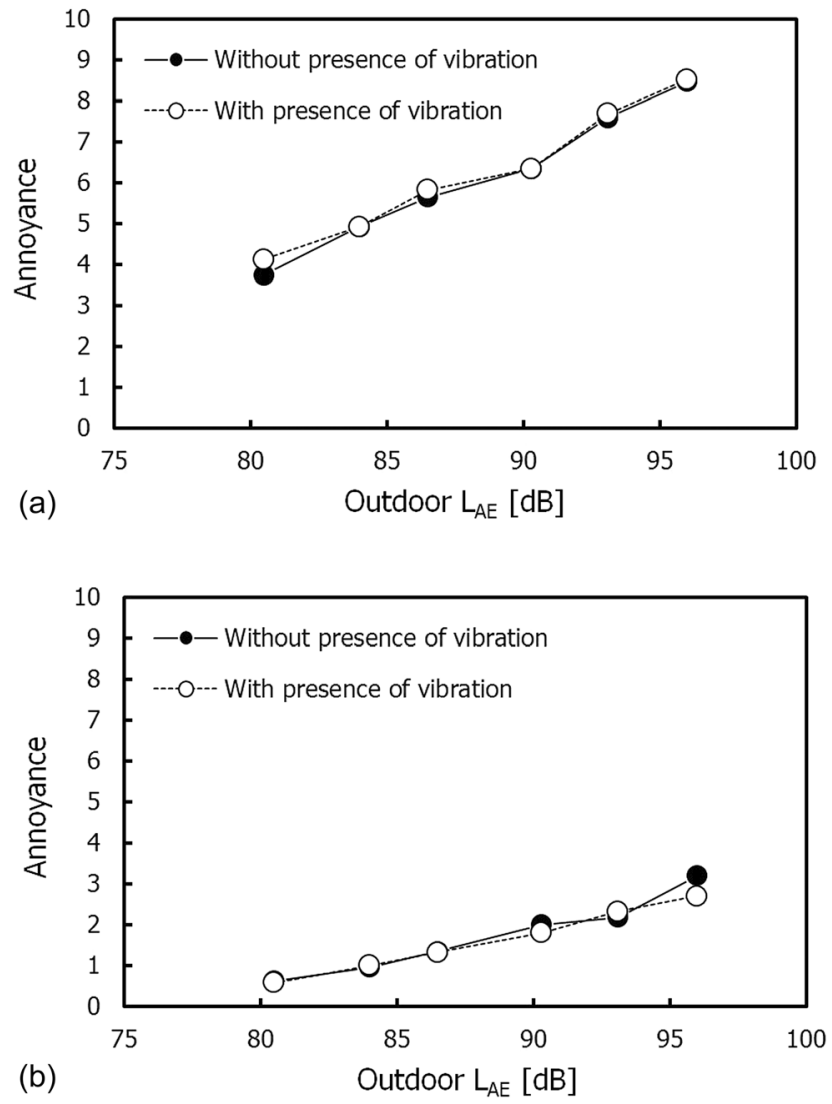

FIG. 6. Mean noise annoyance ratings for tests with and without the presence of vibration as a function of outdoor $L_{\mathrm{AEs}}$ (a) windows-open and (b) windows-closed.

noise annoyance was not significant for the windows-open condition $[F(1,468)=0.75, p>0.38]$ and windows-closed condition $[F(1,468)=0.94, p>0.33]$. It was also observed that the interaction between sessions and sound pressure level was not significant for the windows-open condition $[F(5,468)=0.19, p>0.96]$ or windows-closed condition $[F(5,468)=0.89, p>0.48]$.

TABLE III. Annoyance ratings for both windows-open and windows-closed conditions $\left(M=\right.$ mean annoyance ratings, $\sigma_{m}=$ standard error of the mean).

\begin{tabular}{|c|c|c|c|c|c|c|c|c|}
\hline \multirow[b]{2}{*}{ Windows condition } & \multirow[b]{2}{*}{ Evaluation } & & \multicolumn{6}{|c|}{ Outdoor $L_{\mathrm{AE}}[\mathrm{dB}]$} \\
\hline & & & 96.0 & 93.1 & 90.3 & 86.5 & 84.0 & 80.5 \\
\hline \multirow[t]{6}{*}{ Open } & $\begin{array}{l}\text { Noise annoyance } \\
\text { (without presence of vibration) }\end{array}$ & $M$ & 8.5 & 7.6 & 6.4 & 5.7 & 4.9 & 3.8 \\
\hline & & $\sigma_{m}$ & 1.13 & 1.25 & 1.53 & 1.47 & 1.58 & 1.28 \\
\hline & Total annoyance & $M$ & 9.2 & 8.4 & 7.4 & 6.7 & 5.4 & 4.8 \\
\hline & & $\sigma_{m}$ & 0.75 & 1.21 & 1.30 & 1.38 & 1.22 & 1.31 \\
\hline & $\begin{array}{l}\text { Noise annoyance } \\
\text { (with presence of vibration) }\end{array}$ & $M$ & 8.5 & 7.7 & 6.4 & 5.8 & 4.9 & 4.1 \\
\hline & & $\sigma_{m}$ & 1.09 & 1.32 & 1.37 & 1.27 & 1.44 & 1.24 \\
\hline \multirow[t]{6}{*}{ Closed } & $\begin{array}{l}\text { Noise annoyance } \\
\text { (without presence of vibration) }\end{array}$ & $M$ & 3.2 & 2.2 & 2.0 & 1.4 & 1.0 & 0.6 \\
\hline & & $\sigma_{m}$ & 1.23 & 1.03 & 1.10 & 0.76 & 0.99 & 0.89 \\
\hline & Total annoyance & $M$ & 6.5 & 5.3 & 4.5 & 3.0 & 2.3 & 1.8 \\
\hline & & $\sigma_{m}$ & 1.77 & 1.82 & 1.41 & 1.46 & 1.26 & 1.13 \\
\hline & $\begin{array}{l}\text { Noise annoyance } \\
\text { (with presence of vibration) }\end{array}$ & $M$ & 2.7 & 2.3 & 1.8 & 1.3 & 1.0 & 0.6 \\
\hline & & $\sigma_{m}$ & 1.28 & 1.12 & 0.92 & 1.05 & 0.99 & 0.82 \\
\hline
\end{tabular}




\section{Comparison of noise annoyance with total annoyance}

Figures 7(a) and 7(b) show the noise annoyance and total annoyance ratings obtained from sessions 1 and 2 for two façade conditions. In order to examine the differences between annoyance ratings, the two sessions (noise only and combined sessions) and $L_{\mathrm{AEs}}$ were subjected to an analysis of variance [2 sessions $\times 6$ sound pressure levels]. As shown in Fig. 6(a), total annoyance ratings were significantly greater than noise annoyance ratings $[F(1,468)=40.4, p<0.01]$, and the differences between them were significant at five sound pressure levels, but not for the outdoor $L_{\mathrm{AE}}$ of $84.0 \mathrm{~dB}(p>0.17)$ for the windows-open condition. Interaction between sessions and levels was not significant $[F(5,468)=0.44, p>0.82]$. Similarly, for the windows-closed condition, the ratings were significantly affected by sessions $[F(1,468)=246.9, p<0.01]$ and the interaction between sessions and sound pressure levels was not significant $[F(5,468)=0.89, p>0.48]$. The differences between noise annoyance and total annoyance ratings were significant at all sound levels.

The two façade insulations had slightly different tendencies in the difference between noise annoyance and total annoyance ratings. For the windows-open condition, the differences were constant, which means the contributions of vibration to total annoyance ratings were almost the same at each level. However, for the windows-closed condition with a quiet indoor environment, differences between the noise annoyance and total annoyance ratings increased with an
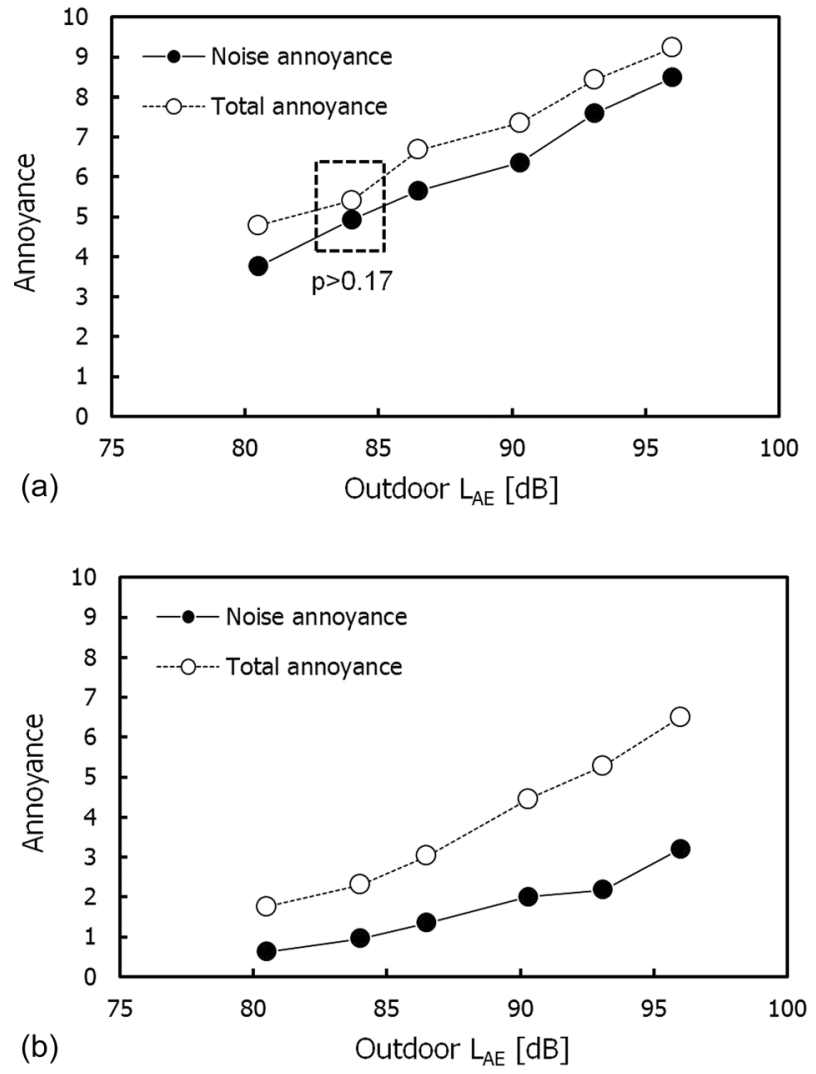

FIG. 7. Mean noise annoyance ratings for tests without the presence of vibration and mean total annoyance ratings as a function of outdoor $L_{\mathrm{AEs}}$; (a) windows-open and (b) windows-closed. increase of vibration levels. This is because vibration annoyance ratings were greater than noise annoyance ratings for the windows-closed condition at locations near the railway.

\section{Vibration annoyance}

Vibration annoyance ratings are plotted in Figs. 8(a) and 8(b) as a function of rms acceleration and VDV, respectively, and mean annoyance ratings are listed in Table IV. Mean vibration annoyance ratings increased as vibration levels increased and were highly correlated with both rms and VDV, giving the same correlation coefficients of $0.98(p<0.01)$.

\section{DISCUSSION}

\section{A. Influences of vibration on noise annoyance}

The laboratory experiment revealed that there were no significant influences of vibration on noise annoyance ratings for either of the two window conditions. These results are consistent with the findings of Howarth and Griffin (1990b), in which vibration did not influence judgments of the noise of conventional trains in the laboratory. However, other studies have found the opposite, reporting a synergetic effect of vibration on the noise annoyance of high-speed trains (Yano et al., 2005; Yokoshima and Tamura, 2005) and the discomfort caused by noise (Huang and Griffin, 2012). The disagreement may be attributed to the different research methodologies and different stimuli. Studies of high speed train noise (Yano et al., 2005; Yokoshima and Tamura,
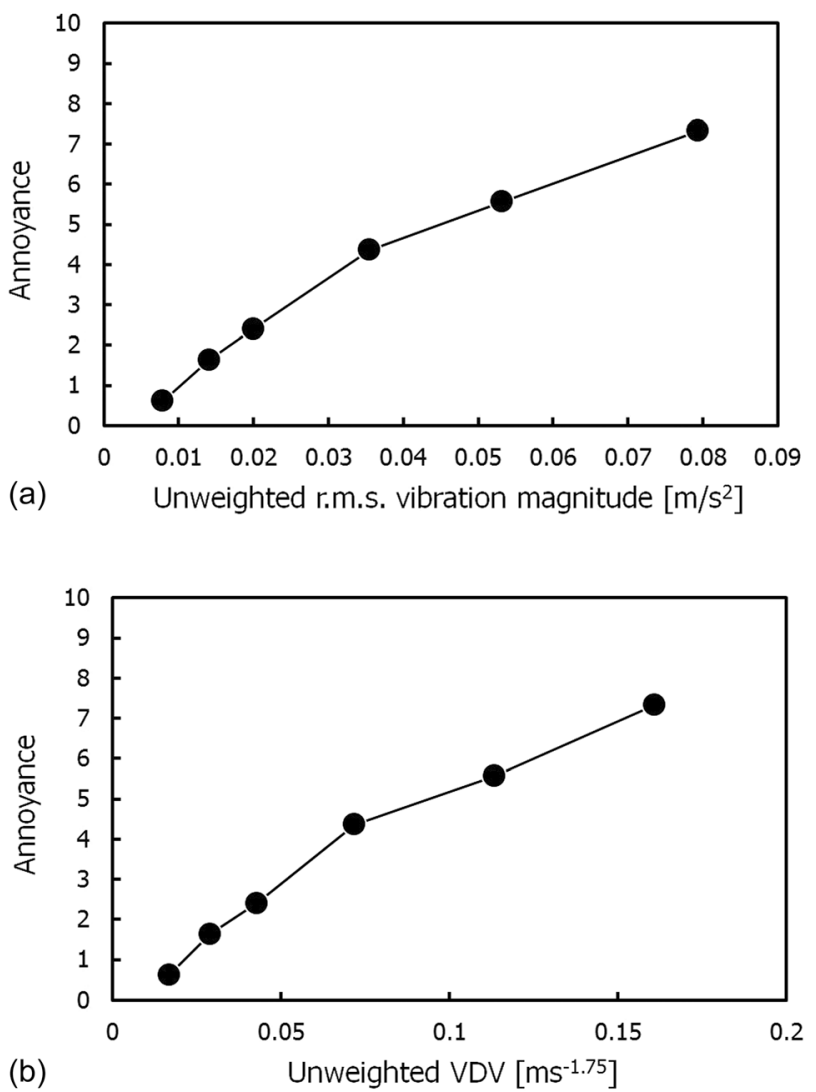

FIG. 8. Mean vibration annoyance ratings; (a) as a function of rms and (b) as a function of VDV. 
TABLE IV. Vibration annoyance ratings $(M=$ mean annoyance ratings, $\sigma_{m}=$ standard error of the mean).

\begin{tabular}{lllllll}
\hline \hline & \multicolumn{6}{c}{ Unweighted rms acceleration level [m/s $\left.{ }^{2}\right]$} \\
\cline { 2 - 7 } & 0.079 & 0.053 & 0.036 & 0.020 & 0.014 & 0.008 \\
\hline$M$ & 7.3 & 5.6 & 4.4 & 2.4 & 1.6 & 0.6 \\
$\sigma_{m}$ & 1.44 & 1.31 & 1.36 & 0.73 & 0.75 & 0.74 \\
\hline \hline
\end{tabular}

2005) employed social surveys with subjects who had longterm exposures to noise and vibration. In contrast, the subjects in this study were only exposed to the high-speed train noise during the study and there was no consideration of the cumulative effect of trains (different numbers of trains or time of day of the train pass-by). In a laboratory experiment, Huang and Griffin (2012) used reproductions of noise and vibration stimuli recorded in an automobile during driving. Their noise levels corresponded to the range levels used in the windows-open condition of the present study, but the vibration was much greater. Huang and Griffin (2012) reported that vibration masked the discomfort of noise but only when the magnitude of vibration was greater than the highest magnitude used in the present study. This study assumed that the buildings were wooden-framed structures, to maximize the amplitudes of the vibration stimuli. Thus, it is expected that vibration-induced by high-speed trains will not have a significant impact on noise annoyance in either masonry or concrete buildings because vibration levels in heavyweight structures are less than in light-weight structures.

\section{B. Influences of inter-subject variability on annoyance}

Several researchers have demonstrated that inter-subject variability has an influence on subjective responses to noise and vibration. Causes of inter-subject variability identified by previous studies include: age (Fields, 1993), gender (Fields, 1993), experience and cultural difference (Jeon et al., 2011), and noise sensitivity (Miedema and Vos, 2003). In the present study, noise and vibration sensitivities as well as cultural difference (ethnicity) were chosen to assess the influence of inter-subject variability on subjective responses.

To investigate the effects of sensitivity on annoyance ratings, the subjects were divided into two groups according to their standardized sensitivity scores, based on the probability density function of the sensitivity scores. Cumulative probability (CP) and standardized score $(z)$ for the two groups were $50 \%$ and 0 , respectively. Nine and 11 subjects belonged to high and low noise sensitivity groups while an equal number of subjects were categorized in the low and high vibration sensitivity groups. Independent $t$-tests were conducted with annoyance ratings as a dependent variable and sensitivity as an independent variable. It was found that vibration sensitivities did not produce significant differences in total annoyance ratings for the façade conditions or vibration annoyance ratings. Contrary to vibration sensitivity, noise sensitivities were associated with significant differences in annoyance ratings. For windows-open conditions there was a general tendency for greater annoyance ratings in the high sensitivity group than in the low sensitivity group, however, differences between the two groups for noise annoyance without the presence of vibration, and for total annoyance were not statistically significant. As shown in Fig. 9, significant differences between the two groups were found with outdoor $L_{\mathrm{AEs}}$ of $80.5,84.0$, and $90.3 \mathrm{~dB}$ for annoyance ratings obtained from the combined noise and vibration condition ( $p<0.05$ for all). For windows-closed conditions, significant differences between the two groups were observed for total annoyance and noise annoyance ratings from the conditions with the presence of vibration. As shown in Figs. 10(a) and 10(b), the difference in total annoyance ratings between the groups was significant only with an outdoor $L_{\mathrm{AE}}$ of $86.5 \mathrm{~dB}(p<0.05)$ while two significant differences in annoyance ratings from combined noise and vibration condition were found with outdoor $L_{\mathrm{AEs}}$ of 93.1 and $96.0 \mathrm{~dB}(p<0.05$ for all). Previous studies have investigated the effect of noise sensitivity on subjective judgment and reactions in noise only conditions (Öhrström, 1995; Miedema and Vos, 2003). The findings of the present study demonstrate that the influence of noise sensitivity on noise annoyance ratings is also significant in combined noise and vibration conditions. However, a limited number of subjects participated in the present study, therefore, it would be necessary to expand the laboratory experiment using substantial more subjects in the future.

During the interviews, all of the Korean subjects said they had experienced traveling by high-speed train, whereas only eight of the ten British subjects replied that they
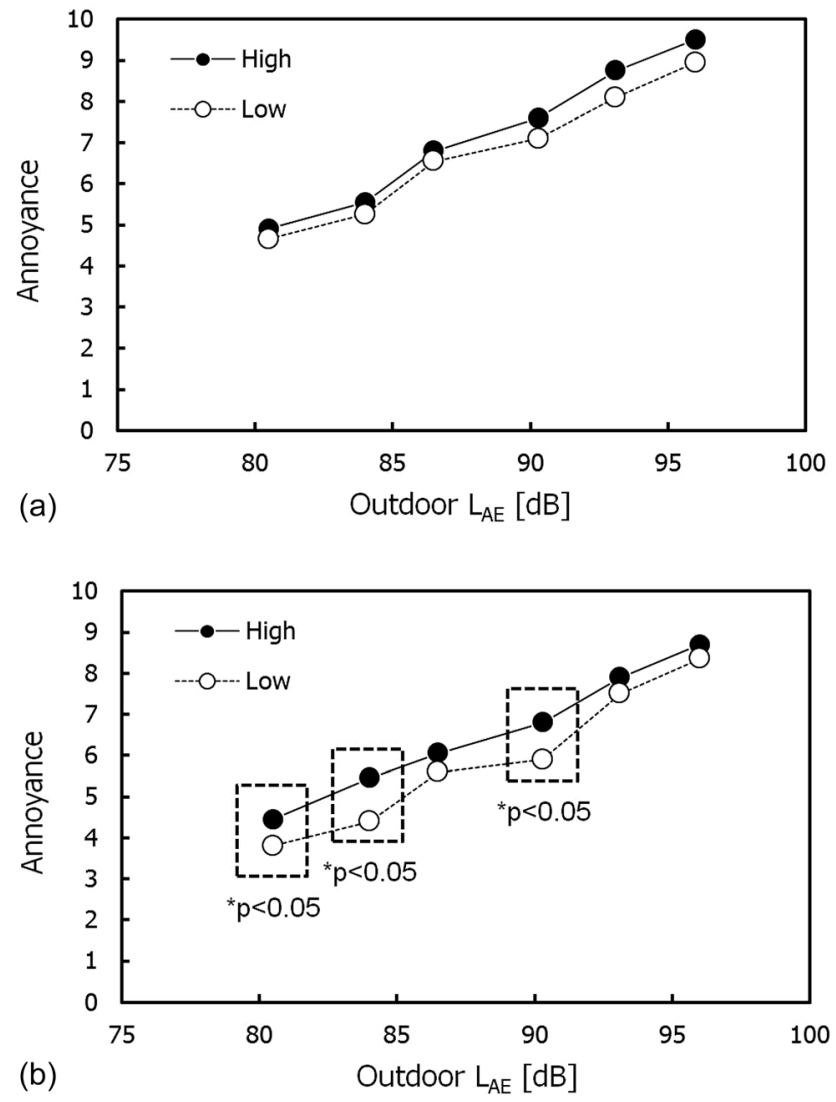

FIG. 9. Mean annoyance ratings for noise sensitivity groups (low and high) in windows-open; (a) total annoyance and (b) noise annoyance in the presence of vibration. 

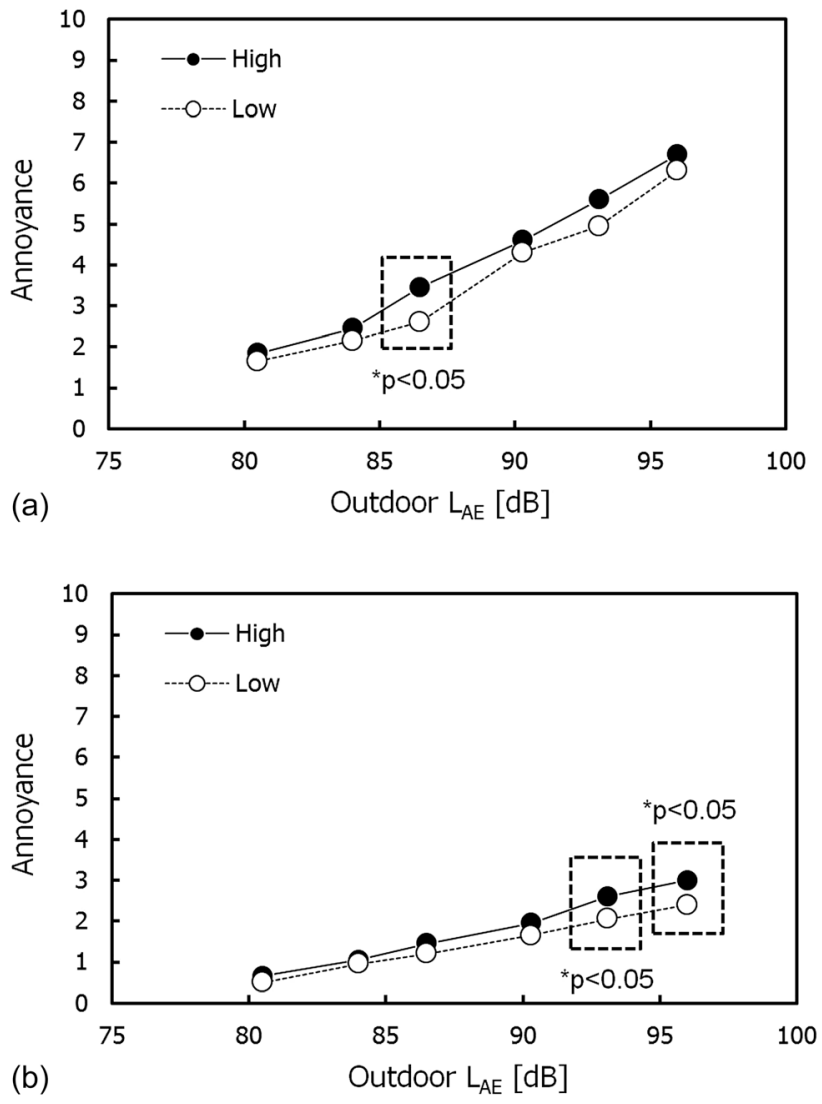

FIG. 10. Mean annoyance ratings for noise sensitivity groups (low and high) in the windows-closed condition; (a) total annoyance and (b) noise annoyance in the presence of vibration.

experienced high-speed train travel. More precisely, six Korean subjects had traveled by high-speed train less than five times while one and three Korean subjects used highspeed train five to ten times or more than ten times, respectively. All of the British subjects with experience of highspeed trains had traveled less than five times. There were no differences in noise and vibration sensitivities between Korean and British subjects. The mean and standard deviation of noise sensitivity for Korean subjects were 5.2 and 1.9, while those for British subjects were 5.9 and 1.5, respectively. Mean vibration sensitivities for Korean and British subjects were also similar (5.9 for Korean and 5.6 for British). Statistical tests were conducted in order to see whether ethnicity (Korean and British) produced significant differences in terms of subjective judgments. Independent $t$-tests were performed with the annoyance ratings as the dependent variable. The results revealed that there were no significant differences between two groups for all façade conditions and sessions. The $p$-values obtained from the independent $t$-tests were larger than 0.22 except for total annoyance ratings of windows-closed condition $(p=0.07)$. This may be because, contrary to expectations, most British subjects had also experienced travel by high-speed train and movie clips including trains decreased fear and increased familiarity with high-speed trains.

\section{Prediction of total annoyance caused by noise and vibration}

Predictions of total annoyance produced by combined noise and vibration were determined using models for predicting annoyance due to combined noise sources. The models adopted in the present study are the dominance model (Rice and Izumi, 1984) and the independent effect model (Taylor, 1982). In the dominance model, the total annoyance is equal to the maximum of the single source annoyance, whereas the independent effect model assumes that separate sources make independent contributions to total annoyance.

In order to evaluate the reliability of the two models, multiple regression analysis was performed in a similar manner to a previous study (Nguyen et al., 2012). The regression equations drawn from the multiple regression analysis are listed in Table V. They represent the relationship between individual annoyance ratings for each source and the total annoyance ratings. The coefficients of determination $\left(R^{2}\right)$ and the standard errors of the estimate were also calculated. For the windows-open condition, the independent effects model was found to be slightly better than the dominance model in terms of the coefficient of determination. The standard error of the independent effects model was also slightly less than that obtained from the dominance model. Standardized regression coefficients of the noise and vibration obtained from the regression equation of the independent effects model were 0.57 and 0.33 , respectively $(p<0.01$ for all). This indicates that noise annoyance has a great effect on total annoyance, more than vibration annoyance. Similarly, the independent effects model $\left(R^{2}=0.72\right)$ estimated the total annoyance slightly better than the dominance model $\left(R^{2}=0.68\right)$ in the regression equations for the windows-closed condition. The standardized regression coefficients for noise and vibration annoyance were 0.38 and 0.55 ( $p<0.01$ for all) respectively, showing the opposite tendency to the results of the windows-open condition. This

TABLE V. Regression equations obtained from prediction models; $A_{T}$ : total annoyance, $A_{D}$ : annoyance score of dominant source, $A_{N}$ : noise annoyance, $A_{V}$ : vibration annoyance.

\begin{tabular}{|c|c|c|c|c|}
\hline Windows condition & Model & Regression equation & $R^{2}$ & Standard error \\
\hline \multirow[t]{2}{*}{ Open } & Dominance & $A_{T}=0.78 A_{D}+2.179$ & $0.69^{\mathrm{a}}$ & 1.099 \\
\hline & Independent effects & $A_{T}=0.54 A_{N}+0.25 A_{V}+2.742$ & $0.72^{\mathrm{a}}$ & 1.037 \\
\hline \multirow[t]{2}{*}{ Closed } & Dominance & $A_{T}=0.733 A_{D}+1.147$ & $0.68^{\mathrm{a}}$ & 1.270 \\
\hline & Independent effects & $A_{T}=0.64 A_{N}+0.48 A_{V}+1.033$ & $0.72^{\mathrm{a}}$ & 1.185 \\
\hline
\end{tabular}

${ }^{\mathrm{a}} p<0.01$. 
shows that the contribution of noise annoyance to total annoyance is dependent on the magnitude of noise stimuli.

\section{Policy implications}

A number of studies (Schultz, 1978; Miedema and Vos, 1998) have reported on the exposure-response relationship for transportation noise sources. Noise regulations in the EU and non-EU countries are developed based on the relationship between exposure to a single source and annoyance. However, the present study demonstrates that total annoyance produced by noise and vibration is greater than noise annoyance, regardless of sound insulation performance of windows or distances from the railway track, and the difference between total annoyance and noise annoyance is significant. This implies that noise annoyance does not reflect a subject's whole reaction to highspeed trains, and train-induced vibration should be considered in the assessment of community response to high-speed trains. Both the dominance model and the independent effects model could be used to predict total annoyance caused by noise and vibration, just as international standard on assessment of environmental noise (ISO 1996-1, 2003) describes the equivalentlevel method for evaluating annoyance caused by exposure to sounds in multi-source environments.

The concept of soundscape has been introduced to integrate auditory information with other sensory modalities (Schafer, 1977) and non-auditory factors influencing soundscape perception have been proposed (Schomer et al., 2010; Jeon et al., 2011). Few studies have examined vibration as a descriptor of soundscape (Schulte-Fortkamp, 2001), but this study implies that global perception of a specific environment can be affected by vibration. The vibration produced by transportation and machinery should be considered as a component of the soundscape when making standards, designing soundscapes, and establishing regulations on the acoustic environment.

\section{CONCLUSIONS}

For noise and vibration conditions similar to those that may be encountered in a building during the passage of a nearby high-speed train, judgments of noise annoyance were not affected by vibration with either a windows-open or a windows-closed condition. Total annoyance caused by combined noise and vibration was significantly greater than noise annoyance with both window conditions, and well predicted by the maximum of the single source annoyance or the integration of individual annoyance ratings. Noise sensitivity had a significant influence on total annoyance as well as noise annoyance, but ethnicity did not influence annoyance.

\section{ACKNOWLEDGMENTS}

This work was supported by the National Research Foundation of Korea (NRF) grant funded by the Korea government (Ministry of Education, Science and Technology, Grant No. NRF-2011-357-D00255).

Chen, X. H., Tang, F., Huang, Z. Y., and Wang, G. T. (2007). "High-speed maglev noise impacts on residents: A case study in Shanghai," Transp. Res. D 12, 437-448.
De Coensel, B., Botteldooren, D., Berglund, B., Nilsson, M. E., De Muer, T., and Lercher, P. (2007). "Experimental investigation of noise annoyance caused by high-speed trains," Acta. Acust. Acust. 93, 589-601.

Fields, J. M. (1979). "Railway noise and vibration annoyance in residential areas,” J. Sound Vib. 66, 445-458.

Fields, J. M. (1993). "Effect of personal and situational variables on noise annoyance in residential areas," J. Acoust. Soc. Am. 93, 2753-2763.

Fields, J. M., and Walker, J. G. (1982). "Comparing the relationships between noise level and annoyance in different surveys: A railway noise vs. aircraft and road traffic comparison,” J. Sound Vib. 81, 51-80.

Hanson, C. E., Towers, D. A., and Meister, L. D. (2005). "High-speed ground transportation noise and vibration impact assessment," HMMH Report No. 293630-4, U.S. Department of Transportation, Federal Railroad Administration, Office of Railroad Development.

Howarth, H. V. C., and Griffin, M. J. (1990a). "The relative importance of noise and vibration from railways," Appl. Ergon. 21, 129-134.

Howarth, H. V. C., and Griffin, M. J. (1990b). "Subjective response to combined noise and vibration: Summation and interaction effects," J. Sound Vib. 143, 443-454.

Howarth, H. V. C., and Griffin, M. J. (1991). "The annoyance caused by simultaneous noise and vibration from railways," J. Acoust. Soc. Am. 89, 2317-2323.

Huang, Y., and Griffin, M. J. (2012). "The effects of sound level and vibration magnitude on the relative discomfort of noise and vibration," J. Acoust. Soc. Am. 131, 4558-4569.

ISO (1993). 9613-1, Acoustics-Attenuation of Sound During Propagation Outdoors-Part 1: Calculation of the Absorption of Sound by the Atmosphere (International Organization for Standardization, Geneva).

ISO (1997). 2631-1, Mechanical Vibration and Shock-Evaluation of Human Exposure to Whole-Body Vibration-Part 1: General Requirements (International Organization for Standardization, Geneva).

ISO (2003). 1996-1, Acoustics-Description, Measurement and Assessment of Environmental Noise-Part 1: Basic Quantities and Assessment Procedures (International Organization for Standardization, Geneva).

Jeon, J. Y., Lee, P. J., Hong, J. Y., and Cabrera, D. (2011). "Non-auditory factors affecting urban soundscape evaluation,” J. Acoust. Soc. Am. 130, 3761-3770.

Jeon, J. Y., Lee, P. J., You, J., and Kang, J. (2010). "Perceptual assessment of quality of urban soundscape with combined noise sources and water sounds," J. Acoust. Soc. Am. 127, 1357-1366.

Jeon, J. Y., Lee, P. J., You, J., and Kang, J. (2012). “Acoustical characteristics of water sounds for soundscape enhancement in urban open spaces," J. Acoust. Soc. Am. 131, 2101-2109.

Jones, C. J. C. (1994). "Use of numerical models to determine the effectiveness of anti-vibration systems for railways," Proc. Inst. Civ. Eng., Transp. 105, 43-51.

Ju, S. H. (2007). "Finite element analysis of structure-borne vibration from high-speed train," Soil Dyn. Earthquake Eng. 27, 259-273.

Klæboea, R., Turunen-Riseb, I. H., Hàrvik, L., and Madshus, C. (2003). "Vibration in dwellings from road and rail traffic-Part II: ExposureEffect relationships based on ordinal logit and logistic regression models," Appl. Acoust. 64, 89-109.

Kurra, S., Morimoto, M., and Maekawa, Z. I. (1999).“Transport noise annoyance-A simulated environment study for road, railway and aircraft noises, Part 1: Overall annoyance," J. Sound Vib. 220, 251-278.

Lambert, J., Champelovier., P., and Vernet, I. (1996). "Annoyance from high speed train noise: A social survey," J. Sound Vib. 193, 21-28.

Lee, P. J., Shim, M. H., and Jeon, J. Y. (2010). "Effects of different noise combinations on sleep, as assessed by a general questionnaire," Appl. Acoust. 71, 870-875.

Miedema, H. M. E., and Vos, H. (1998). "Exposure-response relationships for transportation noise," J. Acoust. Soc. Am. 104, 3432-3445.

Miedema, H. M. E., and Vos, H. (2003). "Noise sensitivity and reactions to noise and other environmental conditions," J. Acoust. Soc. Am. 113, 1492-1504.

Moehler, U. (1988). "Community response to railway noise: A review of social surveys,” J. Sound Vib. 120, 321-332.

Nguyen, T. L., Nguyen, H. Q., Yano, T., Nishimura, T., Sato, T., Morihara, T., and Hashimoto, Y. (2012). "Comparison of models to predict annoyance from combined noise in Ho Chi Minh City and Hanoi," Appl. Acoust. 73, 952-959.

Öhrström, E. (1995). "Effects of low levels of road traffic noise during the night: A laboratory study on number of events, maximum noise levels, and noise sensitivity," J. Sound Vib. 179, 603-615. 
Öhrström, E., Gidlöf-Gunnarsson, A., Ögren, M., and Jerson, T. (2010). "Comparative field studies on the effects of railway and road traffic noise," in Proceedings of the Internoise 2010, Lisbon, Portugal, proceedings CD-Rom.

Paulsen, R., and Kastka, J. (1995). "Effects of combined noise and vibration on annoyance," J. Sound Vib. 181, 295-314.

Peris, E., Woodcock, J., Sica, G., Moorhouse, A. T., and Waddington, D. C. (2012). "Annoyance due to railway vibration at different times of the day," J. Acoust. Soc. Am. 131, EL191-EL196.

Rice, C. G., and Izumi, K. (1984). "Annoyance due to combinations of noises," Proceedings of the Institute of Acoustics Spring Conference, pp. 287-294.

Ryu, J. K., and Jeon, J. Y. (2011). "Influence of noise sensitivity on annoyance of indoor and outdoor noises in residential buildings," Appl. Acoust. 72, 336-340.

Schomer, P., Brown, A. L., Coensel, B. D., Genuit, K., Gjestland, T., Jeon, J. Y., Kang, J., Newman, P., Schulte-Fortkamp, B., and Watts, G. R. (2010). "On efforts to standardize a graphical description of the soundscape concept," in Proceedings of Inter-noise 2010, Lisbon, Portugal, proceedings CD-Rom.

Schomer, P., Mestre, V., Fidell, S., Berry, B., Gjestland, T., Vallet, M., and Reid, T. (2012). "Role of community tolerance level (CTL) in predicting the prevalence of the annoyance of road and rail noise," J. Acoust. Soc. Am. 131, 2772-2786.

Schafer, R. M. (1977). The Tuning of the World (Knopf, New York), pp. $1-301$.

Schulte-Fortkamp, B. (2001). "Soundscapes in the sense of reaction to sound and vibration," J. Acoust. Soc. Am. 109, 2345-2345.

Schultz, T. J. (1978). "Synthesis of social surveys on noise annoyance," J. Acoust. Soc. Am. 64, 377-405.

Taylor, S. M. (1982). "A comparison of models to predict annoyance reactions to noise from mixed sources," J. Sound Vib. 81, 123-138.
Viollon, S., Lavandier, C., and Drake, C. (2002). "Influence of visual setting on sound ratings in an urban environment," Appl. Acoust. 63, 493-511.

Vos, J. (2003). "A- and C-weighted sound levels as predictors of the annoyance caused by shooting sounds, for various façade attenuation types," J. Acoust. Soc. Am. 113, 336-347.

Vos, J. (2004). "Annoyance caused by the sounds of a magnetic levitation train," J. Acoust. Soc. Am. 115, 1597-1608.

Woodroof, H. J., and Griffin, M. J. (1986), "A survey of the effect of railway-induced building vibration on the community," University of Southampton, ISVR Technical Report to British Rail Technical Centre, Derby.

Yano, T., Morihara, T., and Sato, T. (2005). "Community response to Shinkansen noise and vibration: A survey in areas along the Sanyo Shinkansen Line," in Proceedings of Forum Acusticum 2005, Budapest, Hungary, pp. 1837-1841.

Yokoshima, S., Morihara, T., Sano, Y., Ota, A., and Tamura, A. (2011). "Combined annoyance due to the Shinkansen railway noise and vibration," in Proceedings of Internoise 2011, Osaka, Japan, proceedings CD-Rom.

Yokoshima, S., and Tamura, T. (2005). "Community response to Shinkansen Railway vibration," Proceedings of Internoise 2005, Rio de Janeiro, Brazil, proceedings CD-Rom.

Yoo, H. J., Lee, P. J., and Jeon, J. Y. (2010).“Assessment of railway soundscape in rural area," Proceedings of the International Congress on Acoustics 2010, Sydney, Australia, proceedings CD-Rom.

Zapfe, J. A., Saurenman, H., and Fidell, H. (2009). "Ground-borne noise and vibration in buildings caused by rail transit," Report No. D-12, final report for Transit Cooperative Research Program (TCRP).

Zimmer, K., and Ellermerier, W. (1999). "Psychometric properties of four measure of noise sensitivity: A comparison," J. Environ. Psychol. 19, 295-302. 